\title{
True phosphorus digestibility and the endogenous phosphorus outputs associated with brown rice for weanling pigs measured by the simple linear regression analysis technique
}

\author{
H. Yang ${ }^{1,2}$, A. K. Li $i^{3}$, Y. L. Yin ${ }^{1,2,6 \dagger}$, T. J. Li ${ }^{2}$, Z. R. Wang ${ }^{4}$, G. Wu ${ }^{5}$, R. L. Huang ${ }^{2}$, X. F. Kong ${ }^{1,2}$, \\ C. B. Yang ${ }^{2,6}$, P. Kang ${ }^{3}$, J. Deng ${ }^{2}$, S. X. Wang ${ }^{3}$, B. E. Tan ${ }^{2}$, Q. Hu ${ }^{2}$, F. F. Xing ${ }^{2}, X^{2}$. Wu ${ }^{2}$, Q.

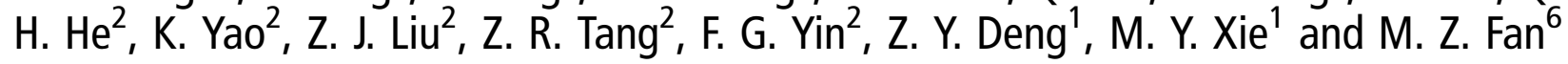

\begin{abstract}
${ }^{1}$ Department of Food Science and Engineering, Nanchang University, Nanchan, Jiangxie 330047, China; ${ }^{2}$ Laboratory of Animal Nutrition and Health and Key Laboratory of Subtropical Agro-ecology, Institute of Subtropical Agriculture, the Chinese Academy of Sciences, Changsha, Hunan 410125, China; ${ }^{3}$ Feed Research Institute, Academy of State Administration of Grain, No. 11, Baiwanzhuang Avenue, Beijing 100037, China; ${ }^{4}$ College of Animal Science, Xinjiang Agricultural University, Urumqi, Xinjiang Uigur Autonomous Region 830052, China; ${ }^{5}$ Department of Animal Science, Texas A\&M University, College Station, Texas 77843-2471, USA; ${ }^{6}$ Centre of Nutritional Modelling, Department of Animal and Poultry Science, University of Guelph, Guelph, Ontario N1G 2W1, Canada
\end{abstract}

(Received 26 November 2005; Accepted 21 August 2006)

The objectives of this study were to determine true phosphorus $(P)$ digestibility, degradability of phytate- $P$ complex and the endogenous $P$ outputs associated with brown rice feeding in weanling pigs by using the simple linear regression analysis technique. Six barrows with an average initial body weight of $12.5 \mathrm{~kg}$ were fitted with a T-cannula and fed six diets according to a $6 \times 6$ Latin-square design. Six maize starch-based diets, containing six levels of $P$ at $0.80,1.36,1.93,2.49,3.04$, and $3.61 \mathrm{~g} / \mathrm{kg}$ per kg dry-matter (DM) intake (DMI), were formulated with brown rice. Each experimental period lasted 10 days. After a 7-day adaptation, all faecal samples were collected on days 8 and 9. Ileal digesta samples were collected for a total of $24 \mathrm{~h}$ on day 10. The apparent ileal and faecal $P$ digestibility values of brown rice were affected $(P<0.01)$ by the $P$ contents in the assay diets. The apparent ileal and faecal $P$ digestibility values increased from -48.0 to $36.7 \%$ and from -35.6 to $40.0 \%$, respectively, as $P$ content increased from 0.80 to $3.61 \mathrm{~g} / \mathrm{kg}$ DMI. Linear relationships $(\mathrm{P}<0.05)$, expressed as $\mathrm{g} / \mathrm{kg} D \mathrm{MI}$, between the apparent ileal and faecal digestible $P$ and dietary levels of $P$, suggested that true $P$ digestibility and the endogenous $P$ outputs associated with brown rice feeding could be determined by using the simple regression analysis technique. There were no differences $(P>0.05)$ in true $P$ digestibility values $(57.7 \pm 5.4$ v. $58.2 \pm 5.9 \%)$, phytate $P$ degradability $(76.4 \pm 6.7$ v. $79.0 \pm 4.4 \%)$ and the endogenous $P$ outputs ( $0.812 \pm 0 . .096$ v. $0.725 \pm 0.083 \mathrm{~g} / \mathrm{kg}$ DMI) between the ileal and the faecal levels. The endogenous faecal $P$ output represented 14 and $25 \%$ of the National Research Council (1998) recommended daily total and available $P$ requirements in the weanling pig, respectively. About $58 \%$ of the total $P$ in brown rice could be digested and absorbed by the weanling pig. Our results suggest that the large intestine of the weanling pigs does not play a significant role in the digestion of $P$ in brown rice. Diet formulation on the basis of total or apparent $P$ digestibility with brown rice may lead to $P$ overfeeding and excessive $P$ excretion in pigs.

Keywords: digestibility, phosphorus, pigs, rice.

\section{Introduction}

Rice is mainly used as human food around the world, especially in Asia, and only some rice by-products are traditionally used as a feedstuff for pigs (Farrell and Hutton, 1990; Yin et al., 1993b). As a primary cultivated crop, early long-grain and non-glutinous rice, also referred to as early

\footnotetext{
${ }^{\dagger}$ E-mail: yyulong2003@yahoo.com.cn
}

season rice or brown rice, has been planted in southern China since ancient times, where it is unsuitable to plant maize and other cereals due to a humid climate. Because of its poor palatability for humans and its low price, brown rice is increasingly used as an alternative cereal grain ingredient in commercial pig diets in southern China (Yin et al., 1993b; Li et al., 2004) and may be used worldwide in the future (Farrell and Hutton, 1990). 
Yang, Li, Yin, Li, Wang, Wu, Huang, Kong, Yang, Kang, Deng, Wang, Tan, Hu, Xing, Wu, He, Yao, Liu, Tang, Yin, Deng, Xie and Fan

However, there is little information on phosphorus (P) bioavailability in brown rice for pigs. Bioavailability of $P$ associated with rice bran has been reported to be relatively low with a large variability (12 to $25 \%$ ), as measured by the apparent digestibility studies and the slope-ratio assay (Jongbloed and Kemme, 1990; Weremko et al., 1997; National Research Council (NRC), 1998). Furthermore, recent studies have suggested that apparent digestibility studies and the slope-ratio assay are limited in assessing true bioavailability of $P$ in feed ingredients for pigs (Fan et al., 2001). True P digestibility in oil meals and cereal grains can be measured by the simple linear regression analysis technique (Fan et al., 2001; Shen et al., 2002).

Therefore, the objectives of this study were to determine true $P$ digestibility, phytate $P$ degradability and the endogenous $\mathrm{P}$ outputs associated with brown-rice feeding at the distal ileal and the faecal levels in weanling pigs.

\section{Material and methods}

\section{Principles of estimation}

Determination of the gastro-intestinal endogenous nutrient outputs by the regression analysis technique relies on establishing linear relationships between apparent digestible and total intake of assay nutrients in diets. The apparent digestible $P$ contents in diets, expressed as $\mathrm{g} / \mathrm{kg}$ dry-matter intake (DMI), are calculated from equation [1] according to previous studies (Yin et al., 2004):

$$
\mathrm{P}_{\mathrm{Ai}}=\mathrm{P}_{\mathrm{Di}} \times \mathrm{D}_{\mathrm{A}}
$$

where $P_{\mathrm{Ai}}$ represents the apparent ileal or faecal digestible $P$ content in the $i$ th diet $(\mathrm{g} / \mathrm{kg} \mathrm{DMI})$, and $D_{\mathrm{A}}$ is the apparent ileal or faecal $\mathrm{P}$ absorption values in the ith diet (\%).

The outputs of $P$ in ileal digesta and faeces consist of both dietary and the endogenous origins. If there are linear relationships between $\mathrm{P}$ outputs in ileal digesta or faeces and the graded levels of $P$ inputs from diets, when expressed as $\mathrm{g} / \mathrm{kg} \mathrm{DMI}$, their relationships can be expressed according to equation [2] (Shen et al., 2002).

$$
P_{A i}=-P_{E}+\left[\left(D_{T} / 100\right) \times P_{D i}\right]
$$

where $P_{\mathrm{Ai}}$ represents the apparent ileal or faecal digestible $P$ content in the ith diet $(\mathrm{g} / \mathrm{kg} \mathrm{DMI})$ determined from equation [1], $P_{E}$ is the endogenous $P$ levels in the ileal digesta or faeces $(\mathrm{g} / \mathrm{kg} \mathrm{DMI}), D_{\mathrm{T}}$ is the true ileal or fecal $P$ absorption values (\%) in the P-containing assay ingredient, and $P_{\mathrm{Di}}$ is the total $\mathrm{P}$ content in the $i$ th diet $(\mathrm{g} / \mathrm{kg} \mathrm{DMI})$.

Equation [2] represents a simple linear regression model in which $P_{\mathrm{Ai}}$ is the dependent variable and $P_{\mathrm{Di}}$ is the independent variable. $P_{\mathrm{E}}$ and $D_{\mathrm{T}}$ are the regression coefficients and are estimated by fitting this simple linear regression model. If there are linear relationships between the apparent ileal and faecal digestible intake and the total intake of dietary $\mathrm{P}$ with significant intercepts, the endogenous $\mathrm{P}$ level in ileal digesta or faeces can then be directly determined by extrapolating the dietary inputs of $P$ to zero by obtaining the intercepts of the linear regression equations $\left(P_{\mathrm{E}}\right)$.

\section{Animals, diets and experimental design}

Six Duroc $\times$ Large White $\times$ Landrace barrows, with an average initial body weight of 12.5 (s.e. $=0.6) \mathrm{kg}$, were obtained from the herd of Hunan Tangrenshen Group Co. Ltd and surgically fitted with a simple T-cannula (i.d. $5 \mathrm{~cm}$ ) at the distal ileum, as previously described (Yin et al., 1991). After surgery, the animals were individually housed in stainless-steel metabolism crates in a temperature-controlled room $\left(22\right.$ to $25^{\circ} \mathrm{C}$ ) and cared for, as previously described (Yin et al., 1991 and 1993a). During a 7-day recovery period, the barrows were fed a regular balanced weaner diet consisting of maize, brown rice, and soyabean meal referred to as the recovery diet (Yin et al., 1991). The diet contained $14.5 \mathrm{MJ} / \mathrm{kg}$ digestible energy, total calcium (Ca) at $7 \mathrm{~g} / \mathrm{kg}$, total $P$ at $6 \mathrm{~g} / \mathrm{kg}$ and $195 \mathrm{~g} / \mathrm{kg}$ crude protein (CP), and met the NRC (1998) requirements of all nutrients.

Six maize starch-based experimental diets were formulated to contain six levels of $P(0.80,1.36,1.93,2 . .49,3.04$, and $3.61 \mathrm{~g} / \mathrm{kg}$ dry matter intake (DMI)) from brown rice. The brown rice contained (as-fed basis) ash $21 \mathrm{~g} / \mathrm{kg}, \mathrm{CP} 88 \mathrm{~g} / \mathrm{kg}$, fat $40 \mathrm{~g} / \mathrm{kg}$, acid-detergent fibre (ADF) $287 \mathrm{~g} / \mathrm{kg}$, neutraldetergent fibre (NDF) $274 \mathrm{~g} / \mathrm{kg}$, acid-detergent lignin (ADL) $59 \mathrm{~g} / \mathrm{kg}$, total starch $764 \mathrm{~g} / \mathrm{kg}$, and Ca $0.80 \mathrm{~g} / \mathrm{kg}$, which were similar to the values reported by Yin et al. (1993b) and Li et al. (2004). The brown rice was ground through a 4.8-mm mesh screen prior to diet incorporation according to standard feed industry practice. Vegetable oil was included to increase the digestible energy content similar to the level recommended by NRC (1998) and to reduce the dustiness of the diets. Saccharose was included to improve the palatability of the diets. $\mathrm{CaCO}_{3}$ was included to maintain an appropriate $\mathrm{Ca}$ to $\mathrm{P}$ ratio. Magnesium sulphate and potassium chloride were included to maintain electrolyte balance in the pigs. Vitamins and trace minerals were supplemented according to NRC (1998). Chromium III oxide was included in the diets as a digestibility marker for the determination of the apparent nutrient digestibility values in the diets.

Following recovery, the barrows were fed one of the six experimental diets (Table 1) according to a $6 \times 6$ Latinsquare design. The pigs were fed twice daily, with an equal amount each meal, at 0800 and $2000 \mathrm{~h}$. The dietary allowances were $500,600,700,800,900$, and $950 \mathrm{~g} /$ day during periods $1,2,3,4,5$, and 6 , respectively.

Each experimental period comprised 10 days. After a 7day adaptation, all faecal samples were collected on days 8 and 9. Ileal digesta samples were collected for a total of $24 \mathrm{~h}$ on day 10. Ileal digesta were collected in soft plastic bags (length $16 \mathrm{~cm}$; i.d. $10 \mathrm{~cm}$ ) which were attached to the barrel of the cannula. The bag contained $10 \mathrm{ml}$ of $10 \%$ sulphuric acid to inhibit microbial activity. The bag was removed and replaced as soon as it was partially filled with at least $50 \mathrm{~g}$ digesta or every $2 \mathrm{~h}$. Digesta were 
immediately frozen at $-20^{\circ} \mathrm{C}$ following removal from the collection bags.

\section{Chemical analyses}

At the conclusion of the experiment, the digesta and faecal samples were freeze-dried, pooled within the same barrow and period for the same diet, ground through a 1-mm mesh screen, and mixed before analysis. The samples of the diets and brown rice were ground similarly. Analyses were performed in duplicate. Analyses for DM were carried out according to procedures of the Association of Official Analytical Chemists (AOAC, 1993). Chromium III oxide was determined according to Saha and Gilbreath (1981) by using an atomic absorption spectrometer (SpectrAA-10/20, Varian, Mulgrave, Australia). Intrinsic phytase activity and phytate $\mathrm{P}$ content were analysed according to the method of Shen et al. (2005).

\section{Calculations and statistical analyses}

The apparent ileal and faecal digestibility values of DM and $P$ in the experimental diets were calculated according to equation [3]:

$$
D_{A i}=100 \%-\left[\left(I_{D} \times P_{I}\right) /\left(I_{1} \times P_{D}\right)\right] \times 100 \%
$$

where $D_{\mathrm{Ai}}$ is apparent ileal or faecal $\mathrm{P}$ digestibility values in the assay diets (\%); $I_{D}$ is digestibility marker concentration in the ith assay diet (\%); $P_{1}$ is $\mathrm{P}$ concentration in ileal digesta or faeces (\%); $P_{\mathrm{D}}$ is $\mathrm{P}$ concentration in the ith assay diet (\%); and $I_{I}$ is digestibility marker concentration in ileal digesta or faeces (\%).

Based on the apparent ileal and faecal $P$ digestibility values, the apparent digestible $P$ values were calculated. The relationship between the apparent digestible $P$ and dietary total $P$ intake at the ileal or the faecal levels could then be examined. True $P$ digestibility and the endogenous $P$ outputs associated with brown rice were calculated according to equation [4] (Shen et al., 2002):

$$
P_{A i}=-P_{E}+\left[\left(D_{T} / 100\right) \times P_{D i}\right]
$$

where $P_{\mathrm{Ai}}$ represents the apparent ileal or faecal digestible $P$ content in the ith diet ( $g / k g$ DMI) determined from equation [3]; $P_{E}$ is the endogenous $P$ levels in the ileal digesta or faeces ( $\mathrm{g} / \mathrm{kg} \mathrm{DMI}) ; D_{\mathrm{T}}$ is the true ileal or faecal $\mathrm{P}$ digestibility values (\%) in the brown rice; and $P_{\mathrm{Di}}$ is the total $P$ content in the ith diet $(\mathrm{g} / \mathrm{kg} \mathrm{DMI})$. Degradability of phytate-P complex at the ileal or the faecal levels were calculated following the same principle according to equation [4].

Data on the $P$ digestibility values were first subjected to three-way ANOVA for a $6 \times 6$ Latin-square design. The intervals between the treatment levels of $P$ were designed to be equal by increasing an equal amount of brown rice $(150 \mathrm{~g} / \mathrm{kg})$ in the diets at the expense of maize starch. The treatment effect was therefore partitioned and tested according to equally spaced orthogonal polynomial analyses (Steel and Torrie, 1980). The ANOVA and the orthogonal polynomial analyses were carried out using the

\begin{tabular}{|c|c|c|c|c|c|c|}
\hline & \multicolumn{6}{|c|}{ Diet } \\
\hline & 1 & 2 & 3 & 4 & 5 & 6 \\
\hline \multicolumn{7}{|l|}{ Ingredients } \\
\hline Saccharose & 25 & 25 & 25 & 25 & 25 & 25 \\
\hline Cellulose & 84.4 & 72 & 59.7 & 47.5 & 35.3 & 2.7 \\
\hline Maize starch & 713 & 563 & 413 & 263 & 113 & 0 \\
\hline Brown rice & 150 & 300 & 450 & 600 & 750 & 900 \\
\hline Vegetable oil & 0 & 9.8 & 19.4 & 29 & 38.6 & 31.5 \\
\hline Salt & 3.5 & 3.5 & 3.5 & 3.5 & 3.5 & 3.5 \\
\hline Vitamin pre-mix ${ }^{\dagger}$ & 1.5 & 1.5 & 1.5 & 1.5 & 1.5 & 1.5 \\
\hline Trace-mineral pre-mix ${ }^{\ddagger}$ & 1 & 1 & 1 & 1 & 1 & 1 \\
\hline Chromium III oxide & 2.5 & 2.5 & 2.5 & 2.5 & 2.5 & 2.5 \\
\hline $\mathrm{CaCO}_{3}$ & 4.1 & 6.7 & 9.4 & 12 & 14.6 & 17.3 \\
\hline Magnesium sulphate & 5 & 5 & 5 & 5 & 5 & 5 \\
\hline Potassium chloride & 10 & 10 & 10 & 10 & 10 & 10 \\
\hline Total & 1000 & 1000 & 1000 & 1000 & 1000 & 1000 \\
\hline \multicolumn{7}{|l|}{ Nutritive values: } \\
\hline Crude protein (\%) & 2 & 3.99 & 5.99 & 7.98 & 9.98 & 11.97 \\
\hline Digestible energy (MJ/kg) & 14.49 & 14.5 & 14.5 & 14.5 & 14.5 & 14.5 \\
\hline $\mathrm{Ca}(\%)$ & 0.16 & 0.27 & 0.37 & 0.48 & 0.58 & 0.69 \\
\hline Total P (\%) & 0.07 & 0.12 & 0.17 & 0.22 & 0.27 & 0.32 \\
\hline $\mathrm{Ca} / \mathrm{P}$ ratio $(\%)$ & 2.2 & 2.2 & 2.2 & 2.2 & 2.2 & 2.2 \\
\hline
\end{tabular}

Table 1 Composition of experimental diets ( $g / k g$ as-fed basis)

${ }^{\dagger}$ Supplied the following vitamins (mg/kg diet): retinyl palmitate, 13.2; cholecalciferol, 0.84; all-rac- $\alpha$-tocopherol acetate, 96.0; menadione, 3.0; riboflavin, 5.25; niacin, 22.5; D-pantothenic acid, 15.0; cyanocobalamin, 0.026; thiamine, 1.5; choline chloride, 750.0; pyridoxine, 2.25; D-biotin 0.08; folic acid, 0.45 .

${ }^{\ddagger}$ Supplied the following minerals (mg/kg diet): $\mathrm{FeSO}_{4} \cdot \mathrm{H}_{2} \mathrm{O}, 152 ; \mathrm{ZnCO}_{3}, 95.9 ; \mathrm{MnSO}_{4} \cdot \mathrm{H}_{2} \mathrm{O}, 6.2 ; \mathrm{CuSO}_{4} \cdot 5 \mathrm{H}_{2} \mathrm{O}, 11.8 ; \mathrm{KI}_{1} 0.6 ; \mathrm{Na}_{2} \mathrm{SeO}_{3}, 0.3$. 
Yang, Li, Yin, Li, Wang, Wu, Huang, Kong, Yang, Kang, Deng, Wang, Tan, Hu, Xing, Wu, He, Yao, Liu, Tang, Yin, Deng, Xie and Fan

general linear procedures of Statistical Analysis Systems Institute (SAS, 1988). Related linear and curvilinear regression analyses were also conducted using SAS. The comparison of true $\mathrm{P}$ digestibility, phytate $\mathrm{P}$ degradability and the endogenous $P$ outputs between the ileal and the faecal levels was conducted according to the pooled $t$ test of SAS.

\section{Results}

All the piglets remained healthy throughout the experiment. Post-mortem examination, conducted at the conclusion of the experiment, revealed no adhesions or other intestinal abnormalities.

The brown rice used in the present study contained $116.9 \pm 6.1$ FTU per $\mathrm{kg}$ DM of intrinsic phytase activity as well as $3.60 \mathrm{~g} / \mathrm{kg}$ total $P$ and $2.53 \mathrm{~g} / \mathrm{kg}$ phytate $P$ on as-fed basis. Thus, this test brown rice sample contained about $70 \%$ of its total $P$ as phytate $P$.

Graded levels of dietary CP, Ca and P intake, as a result of graded levels of brown rice inclusion, apparently did not affect the normal digestive function of the weanling pigs, as was reflected by changes in apparent DM digestibility values (Table 2). There was a linear decrease $(P<0.01)$ in the apparent ileal and faecal DM digestibility values from diets 1 to 6 , which was a direct result of replacing maize starch with brown rice, indicating that brown rice has a lower apparent ileal and faecal DM digestibility values than maize starch. There were quadratic increases $(P<0.05)$ in the apparent ileal and faecal $P$ digestibility values in brown rice when the dietary $P$ content was increased from 0.8 to $3.6 \mathrm{~g} / \mathrm{kg}$ DM diet (Table 2). This increase was 84.7 and 75.6 percentage units for the apparent ileal and faecal $P$ digestibility values, respectively (Table 2 ). Meanwhile, there were no animal and period effects $(P>0.05)$ on the apparent $\mathrm{DM}$ and $\mathrm{P}$ digestibility values.

There were linear relationships $(P<0.05)$ between the apparent ileal and the faecal digestible $P$ intake and the total intake of dietary $\mathrm{P}$ (Figure 1). Thus, true P digestibility and the endogenous $P$ outputs associated with brown rice could be obtained by the simple linear regression analysis technique. There were no differences $(P>0.05)$ in true $P$ digestibility values $(57.7 \pm 5.4$ v. $58.2 \pm 5.9 \%)$, and the endogenous $P$ outputs $(0.812 \pm 0.096$ v. $0.725 \pm 0.083 \mathrm{~g} /$ $\mathrm{kg}$ DMI) associated with the brown rice between the ileal and the faecal levels.

There were also linear relationships $(P<0.05)$ between the apparent ileal and the faecal degradable Phytate $P$ intake and the dietary phytate $P$ intake (Figure 2), suggesting that true phytate $P$ degradability at the ileal and the faecal levels could also be estimated by the simple linear regression analysis technique. There were no differences $(P>0.05)$ in phytate $P$ degradability $(76.4 \pm 6.7 v$. $79.0 \pm 4.4 \%$ ) between the ileal and the faecal levels.

Based on true $P$ digestibility values and the endogenous $P$ outputs, dietary $P$ inputs and total $P$ flows in ileal digesta and faeces were further partitioned (Tables 3 and 4). The patterns of total $P$ and phytate $P$ flows were similar between ileal digesta and faeces. In general, there were linear increases $(P<0.05)$ in the total ileal $P$ and faecal $P$ outputs, expressed as $\mathrm{g} / \mathrm{kg} \mathrm{DMI}$, as dietary $\mathrm{P}$ levels increased. Of note, ileal and faecal outputs of $P$ of dietary origin showed linear patterns of increases with dietary $P$ levels $(P<0.05)$ when the values were expressed as $g / k g$ DMI (Tables 3 and 4). Endogenous $P$ flows, expressed as g/ $\mathrm{kg} \mathrm{DMl}$, were similar $(P>0.05)$ between the ileal and the faecal measurements, and were not affected by dietary $P$ levels (Tables 3 and 4).

The linear relationships between the apparent ileal and the faecal digestible intake or the total intake of dietary $P$ indicate that the endogenous $P$ levels, expressed as $\mathrm{g} / \mathrm{kg}$ DMI, are constant and independent of dietary $P$ levels (Figure 3). Thus, differences in the dietary levels of $P$ had dramatic effects on the apparent ileal and faecal $P$ digestibility values, but did not affect true $P$ digestibility values (Figure 3). These results show that the endogenous $P$ contributions have a greater effect on apparent digestibility values at low levels of dietary P compared with at elevated levels.

Table 2 Apparent ileal and faecal dry matter and phosphorus (P) digestibility values (\%) in weanling pigs fed the brown rice-based diets ${ }^{\dagger}$

\begin{tabular}{|c|c|c|c|c|c|c|c|}
\hline & \multicolumn{6}{|c|}{ Diet } & \multirow[b]{2}{*}{ s.e. $^{\ddagger}$} \\
\hline & 1 & 2 & 3 & 4 & 5 & 6 & \\
\hline $\begin{array}{l}\text { Dietary P levels (g/kg DM diet) } \\
\text { Ileal digestibility }\end{array}$ & 0.80 & 1.36 & 1.93 & 2.49 & 3.04 & 3.61 & - \\
\hline Dry matter ${ }^{\S, l \mid}$ & 91.7 & 90.4 & 89.1 & 88.3 & 87.8 & 87.5 & 0.96 \\
\hline Phosphorus" & -48.0 & 6.8 & 13.8 & 22.0 & 30.5 & 36.7 & 5.4 \\
\hline \multicolumn{8}{|l|}{ Faecal digestibility } \\
\hline Dry matter ${ }^{\S, \|}$ & 95.9 & 95.3 & 94.6 & 94.4 & 93.7 & 93.5 & 0.5 \\
\hline Phosphorus & -35.6 & 7.0 & 23.2 & 30.0 & 30.6 & 40.0 & 5.9 \\
\hline
\end{tabular}

\footnotetext{
${ }^{\dagger}$ Refer to Table 1 for details of the diets.

${ }^{\ddagger}$ Pooled s.e. $(n=6)$.

$\S$ Digestibility in the experimental diets.

"Linear effect $(P<0.01)$.

"Quadratic effect $(P<0.05)$.
} 
(a)
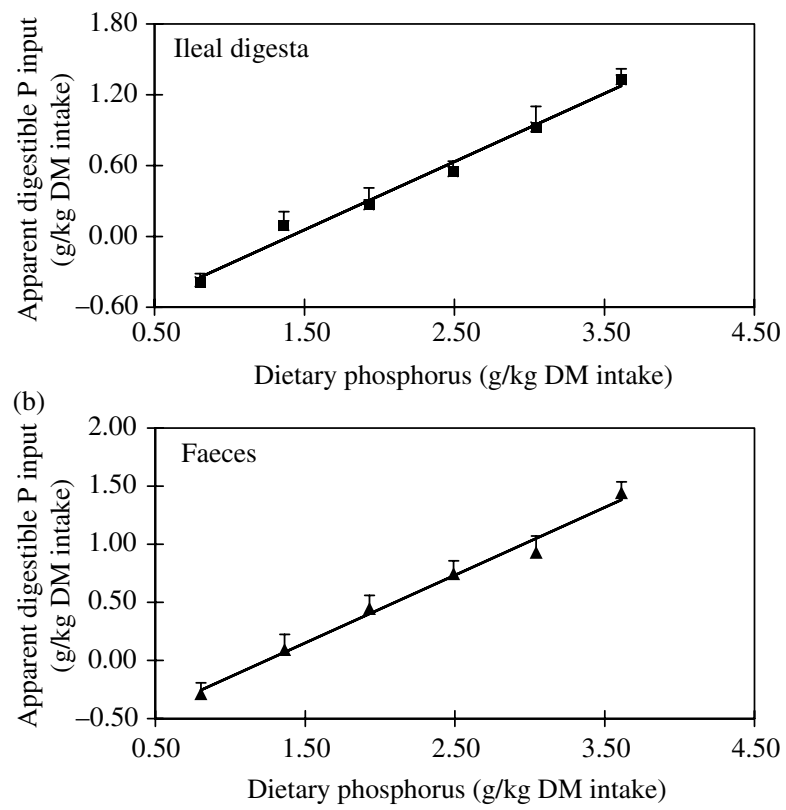

Figure 1 Linear relationships between the apparent ileal $(\boldsymbol{\square})$ and faecal ( $\mathbf{A})$ digestible dietary phosphorus (P) (y: g/kg dry matter (DM) intake, mean \pm s.e., $n=6$, for each data point) or the dietary total $P$ levels ( $x: \mathrm{g} / \mathrm{kg}$ DM intake) in weanling pigs fed the brown rice-based diets. (a) In ileal digesta: $y=0.578 x-0.812, n=36, r^{2}=0.854, P<0.05$. (b) In faeces: $y=0.584 x-0.725, n=36, r^{2}=0.869, P<0.05$.
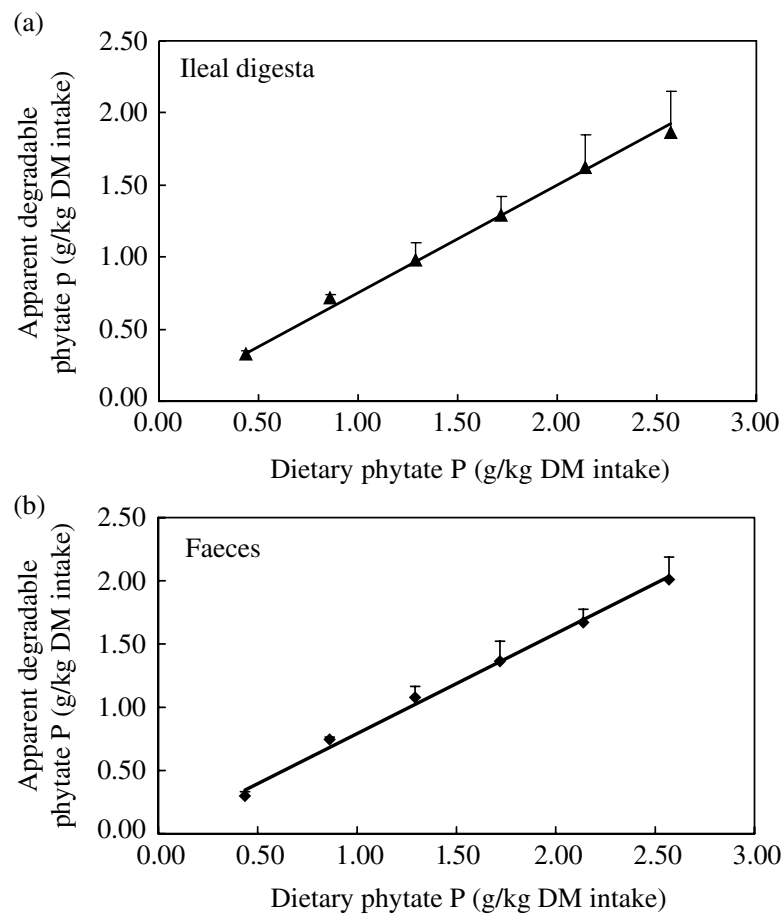

Figure 2 Linear relationships between the ileal $(\mathbf{\Delta})$ and faecal $(\bullet)$ degradable phytate phosphorus (P) ( $y$ : g/kg dry matter (DM) intake, mean \pm s.e., $n=6$, for each data point) and the dietary phytate $P$ inputs ( $x$ : $\mathrm{g} / \mathrm{kg}$ DM intake) in weanling pigs fed brown rice-based diets varying from low to high in total $P$ and phytate- $P$ contents. (a) In ileal digesta: $y=0.7176 x, n=36, r^{2}=0.75, P<0.05$. (b) In faeces: $y=0.7789 x, n=36, r^{2}=0.88, P<0.05$.

\section{Discussion}

The main goal of this study was to measure true $P$ digestibility and the endogenous $P$ associated with brown rice for weanling pigs. The simple linear regression analysis technique has been successfully employed to determine true $P$ digestibility values and the endogenous $P$ outputs associated with soya-bean meal feeding in pigs (Fan et al., 2001, Ajakaiye et al., 2003). This technique has also been found to be applicable for maize in growing pigs (Shen et al., 2002). The P contents, ranging from 1.1 to $4.3 \mathrm{~g} / \mathrm{kg}$ $\mathrm{DMI}$ and from 0.67 to $2.83 \mathrm{~g} / \mathrm{kg} \mathrm{DMI}$, were used in the previous studies involving soya-bean meal in weanling pigs (Fan et al., 2001) and maize for growing pigs (Shen et al., 2002), respectively, whereas dietary $P$ contents varied from 0.80 to $3.61 \mathrm{~g} / \mathrm{kg} \mathrm{DMI}$ in the present study with brown rice (Table 2). Collectively, our results indicate that $P$ contents in the brown rice were about 30\% lower than those in soya-bean meal (Fan et al., 2001), but were approximately $20 \%$ higher than those in maize (Shen et al., 2002). Despite differences in dietary $\mathrm{P}$ contents and gradients among brown rice in this study, soya-bean meal (Fan et al., 2001) and maize (Shen et al., 2002) there were linear relationships $(P<0.05)$ between the ileal and faecal outputs or inputs of dietary $P$, and between the apparent ileal and fecal digestible $\mathrm{P}$ intake or the total intake of dietary $\mathrm{P}$ (Figure 1), when expressed as $\mathrm{g} / \mathrm{kg} \mathrm{DMI}$ in these ingredients. These results have proved that true $P$ digestibility values and the endogenous $P$ outputs associated with the feeding of brown rice for weanling pigs could be determined by the simple linear regression analysis technique.

An interesting finding from this study is that the endogenous $P$ output $(0.812 \pm 0.096 \mathrm{~g} / \mathrm{kg} \mathrm{DMI})$ in the distal ileal digesta of weanling pigs was similar to that $(0.725 \pm 0.083 \mathrm{~g} / \mathrm{kg} \mathrm{DMI})$ in faeces. Of note, the distal ileal and faecal endogenous $P$ outputs were $0.86 \pm 0.09$ and $0.31 \pm 0.06 \mathrm{~g} / \mathrm{kg} \mathrm{DMl}$, respectively, in weanling pigs associated with soya-bean meal feeding (Fan et al., 2001). The distal ieal endogenous $\mathrm{P}$ outputs in weanling pigs were similar between brown rice and soya-bean meal feeding $(0.59 \pm 0.18 \mathrm{~g} / \mathrm{kg} \mathrm{DMI})$, but piglets fed the brown rice-based diet had a relatively high faecal endogenous output when compared with soya-bean meal feeding $(0.31 \pm 0.06 \mathrm{~g} / \mathrm{kg} \mathrm{DMI}$ ) (Ajakaiye et al., 2003). For comparison, ileal and faecal endogenous $P$ outputs were $0.693 \pm 0.128$ and $0.670 \pm 0.160 \mathrm{~g} / \mathrm{kg} \mathrm{DMl}$, respectively, in growing pigs fed the maize-based diet (Shen et al., 2002). Intrinsic differences among feed ingredients and possibly differences among types of pigs used were likely responsible for these discrepancies.

Total and available $\mathrm{P}$ requirements were recommended to be 0.60 and $0.32 \%$, respectively, on an as-fed basis, for pigs between 10 and $20 \mathrm{~kg}$ body weight (NRC, 1998). In this study, the ileal endogenous $P$ output associated with brown rice feeding represents about $15 \%$ of the animal's $(10$ to $20 \mathrm{~kg}$ ) daily requirement for total $P$ and $28 \%$ of the animal's daily requirement for available $P$, respectively. 
Yang, Li, Yin, Li, Wang, Wu, Huang, Kong, Yang, Kang, Deng, Wang, Tan, Hu, Xing, Wu, He, Yao, Liu, Tang, Yin, Deng, Xie and Fan

Table 3 Dietary phosphorus $(P)$ and phytate $P$ input and the partitioning of phosphorus and phytate $P$ flow in the distal ileal digesta of the weanling pigs fed the brown rice-based diets containing various levels of total $P$ and phytate $P^{\dagger}$

\begin{tabular}{|c|c|c|c|c|c|c|c|}
\hline & \multicolumn{6}{|c|}{ Diet } & \multirow[b]{2}{*}{ s.e. } \\
\hline & 1 & 2 & 3 & 4 & 5 & 6 & \\
\hline Total dietary $P$ input (g/kg DM intake) & 0.80 & 1.36 & 1.93 & 2.49 & 3.04 & 3.61 & - \\
\hline Dietary phytate $P$ input (g/kg DM intake) & 0.44 & 0.86 & 1.29 & 1.72 & 2.14 & 2.57 & - \\
\hline Apparent ileal digestible P (g/kg DM intake $)^{\S}$ & -0.39 & 0.09 & 0.27 & 0.55 & 0.93 & 1.33 & 0.10 \\
\hline True ileal digestible P (g/kg DM intake) & 0.46 & 0.79 & 1.11 & 1.44 & 1.76 & 2.08 & - \\
\hline Apparent ileal degradable phytate $\mathrm{P}(\mathrm{g} / \mathrm{kg} \mathrm{DM} \text { intake })^{\S}$ & 0.33 & 0.72 & 0.98 & 1.30 & 1.62 & 1.86 & 0.13 \\
\hline \multicolumn{8}{|l|}{ Total ileal P output } \\
\hline $\mathrm{g} / \mathrm{kg}$ DM digesta ${ }^{\S}$ & 14.39 & 14.48 & 15.62 & 17.33 & 17.72 & 18.57 & 1.38 \\
\hline $\mathrm{g} / \mathrm{kg} \mathrm{DM}$ intake ${ }^{\S}$ & 1.19 & 1.27 & 1.66 & 1.94 & 2.12 & 2.28 & 0.10 \\
\hline \multicolumn{8}{|l|}{ Ileal phytate $P$ output } \\
\hline $\mathrm{g} / \mathrm{kg} \mathrm{DM}$ digesta ${ }^{\S}$ & 1.31 & 1.62 & 2.61 & 3.75 & 4.62 & 5.88 & 1.28 \\
\hline $\mathrm{g} / \mathrm{kg} \mathrm{DM}$ intake ${ }^{\S}$ & 0.11 & 0.15 & 0.31 & 0.42 & 0.52 & 0.70 & 0.13 \\
\hline \multicolumn{8}{|l|}{ Ileal endogenous P output } \\
\hline g/kg DM digestall & 6.91 & 5.21 & 5.13 & 5.26 & 4.59 & 4.06 & 0.62 \\
\hline $\mathrm{g} / \mathrm{kg}$ DM intake & 0.85 & 0.69 & 0.85 & 0.89 & 0.83 & 0.76 & 0.10 \\
\hline \multicolumn{8}{|l|}{ Ileal P output of dietary origin } \\
\hline $\mathrm{g} / \mathrm{kg}$ DM digesta ${ }^{\S}$ & 7.48 & 9.27 & 10.48 & 12.07 & 13.08 & 14.51 & 0.88 \\
\hline $\mathrm{g} / \mathrm{kg} \mathrm{DM}$ intake $\mathrm{s}^{\S}$ & 0.34 & 0.58 & 0.82 & 1.05 & 1.29 & 1.53 & - \\
\hline
\end{tabular}

${ }^{\dagger}$ Refer to Table 1 for details of the diets.

${ }^{\ddagger}$ Pooled s.e. $(n=6)$.

$\S$ Linear effect $(P<0.05)$.

"Quadratic effect $(P<0.05)$.

Faecal endogenous $\mathrm{P}$ output represents about $14 \%$ of the animal's daily requirement for total $P$ and $25 \%$ of the animal's (10 to $20 \mathrm{~kg}$ ) daily requirement for available $P$, respectively. Therefore, faecal endogenous $P$ output contributes to a significant portion of the daily $P$ requirement and to an inevitable source of metabolic $P$ loss.

The true ileal and faecal $P$ digestibility values were similar in brown rice for weanling pigs $(57.8 \pm 5.4 \mathrm{~V}$.

Table 4 Dietary phosphorus $(P)$ and phytate $P$ input and the partitioning of $P$ and phytate $P$ flow in faeces of the weanling pigs fed brown rice meal-based diets varying from low to high in total $P$ and phytate- $P$ contents ${ }^{\dagger}$

\begin{tabular}{|c|c|c|c|c|c|c|c|}
\hline & \multicolumn{6}{|c|}{ Diet } & \multirow[b]{2}{*}{ s.e. $^{\neq}$} \\
\hline & 1 & 2 & 3 & 4 & 5 & 6 & \\
\hline Total dietary $P$ input (g/kg DM intake) & 0.80 & 1.36 & 1.93 & 2.49 & 3.04 & 3.61 & - \\
\hline Dietary phytate $P$ input (g/kg DM intake) & 0.44 & 0.86 & 1.29 & 1.72 & 2.14 & 2.57 & - \\
\hline Apparent faecal digestible P (g/kg DM intake $)^{\S}$ & -0.29 & 0.10 & 0.45 & 0.75 & 0.93 & 1.44 & 0.08 \\
\hline True faecal digestible P (g/kg DM intake) & 0.47 & 0.79 & 1.12 & 1.45 & 1.77 & 2.10 & - \\
\hline Apparent faecal degradable phytate $\mathrm{P}$ (g/kg DM intake) ${ }^{\S}$ & 0.30 & 0.75 & 1.08 & 1.37 & 1.67 & 2.01 & 0.08 \\
\hline \multicolumn{8}{|l|}{ Total faecal P output } \\
\hline g/kg DM faeces ${ }^{\S}$ & 26.88 & 26.92 & 29.24 & 32.17 & 34.28 & 34.45 & 2.16 \\
\hline $\mathrm{g} / \mathrm{kg} \mathrm{DM}$ intake $\mathrm{f}^{\S}$ & 1.09 & 1.27 & 1.48 & 1.75 & 2.11 & 2.17 & 0.08 \\
\hline \multicolumn{8}{|l|}{ Faecal phytate P output } \\
\hline $\mathrm{g} / \mathrm{kg}$ DM faeces ${ }^{\S}$ & 3.39 & 2.48 & 3.64 & 5.60 & 7.42 & 8.18 & 1.11 \\
\hline $\mathrm{g} / \mathrm{kg} \mathrm{DM}$ intake $\mathrm{s}^{\S}$ & 0.14 & 0.12 & 0.21 & 0.35 & 0.47 & 0.56 & 0.08 \\
\hline \multicolumn{8}{|l|}{ Endogenous faecal P output } \\
\hline g/kg DM faeces" & 12.53 & 9.87 & 8.59 & 8.32 & 8.65 & 6.81 & 0.92 \\
\hline g/kg DM intake & 0.75 & 0.70 & 0.67 & 0.70 & 0.84 & 0.66 & 0.08 \\
\hline \multicolumn{8}{|l|}{ Faecal $\mathrm{P}$ output of dietary origin } \\
\hline g/kg DM faeces ${ }^{\S}$ & 14.35 & 17.05 & 20.65 & 23.86 & 25.63 & 27.64 & 1.68 \\
\hline $\mathrm{g} / \mathrm{kg} \mathrm{DM}$ intake $\mathrm{s}^{\S}$ & 0.34 & 0.57 & 0.81 & 1.04 & 1.27 & 1.51 & - \\
\hline
\end{tabular}

${ }^{\dagger}$ Refer to Table 1 for details of the diets.

${ }^{\ddagger}$ Pooled s.e. $(n=6)$.

$\S$ Linear effect $(P<0.05)$.

"Quadratic effect $(P<0.05)$. 

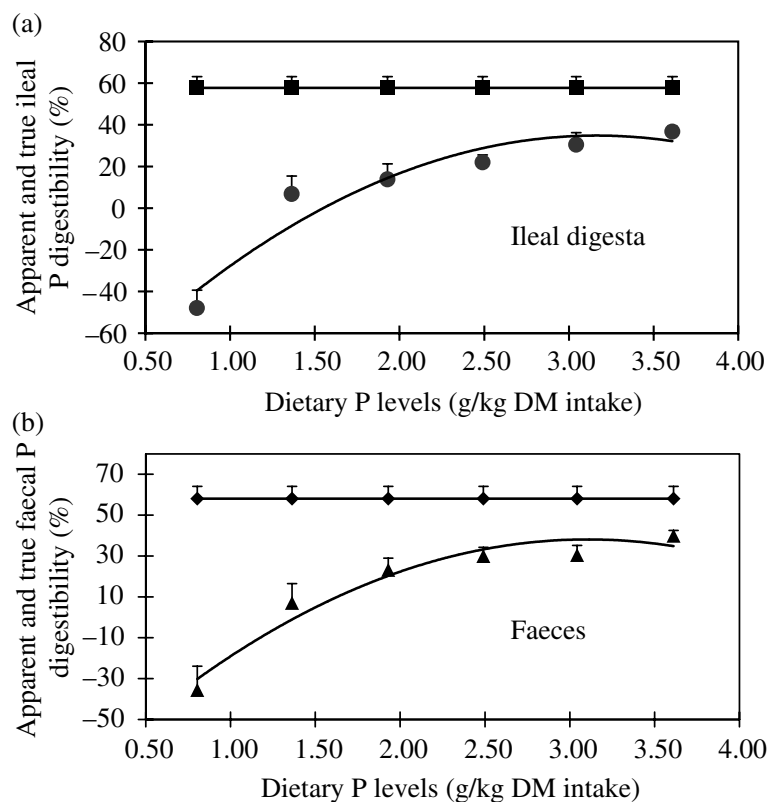

Figure 3 Effects of dietary phosphorus (P) levels [( $/ \mathrm{kg}$ dry matter (DM) intake] on apparent ( $\bullet$ or $\mathbf{\Delta}, \%$, mean \pm s.e., $n=6$, for each data point) and true ( $\square$ or $\bullet, \%$, mean \pm s.e., $n=36$, for each data point) ileal and faecal $P$ digestibility values in weanling pigs fed brown rice-based diets containing various $P$ levels. (a) Ileal digestibility values: the quadratic relationship between apparent ileal $P$ digestibility values $(Y, \%)$ and the dietary levels of $P\left(x, g / k g\right.$ DM diet), $Y=-13.36 x^{2}+84.54 x-98.93$, $n=36, R^{2}=0.77, P<0.05$. (b) Faecal digestibility values: the quadratic relationship between apparent faecal $P$ digestibility values $(Y, \%)$ and the dietary levels of $P(x, \mathrm{~g} / \mathrm{kg} \mathrm{DM}$ diet $), Y=-12.91 x^{2}+80.16 x-86.33$, $n=36, R^{2}=0.75, P<0.05$.

$58.4 \pm 5.9 \%$ ). This finding again supports the view that the large intestine does not play a significant role in the absorption of exogenous $P$ (Jongbloed et al., 1992; Liu et al., 2000; Fan et al., 2001; Shen et al., 2002; Ajakaiye et al., 2003). True $P$ digestibility values determined in this study $(58 \%)$ suggest that an average of $58 \%$ of total $P$ in brown rice could be digested and absorbed by weanling pigs. Phytate $P$ represented about $70 \%$ of the total $P$ in the brown rice sample used in this study. In addition, the significant phytate $\mathrm{P}$ degradability $(76 \%)$ at the distal ileal level due to the combined actions of intrinsic phytase and microbes was likely responsible for the relatively high true faecal $P$ digestibility associated with the brown rice. There are few reports in the literature of true $P$ digestibility or phytate $P$ degradability in brown rice for comparison.

In conclusion, the simple linear regression analysis technique is valid for the determination of true $P$ digestibility and the gastro-intestinal endogenous $P$ outputs associated with brown rice in weanling pigs. The large intestine does not play a significant role in the digestive utilisation of both the exogenous and the endogenous $P$ in weanling pigs when brown rice is the source of dietary $P$. True rather than apparent faecal $P$ digestibility in brown rice should be determined and used in diet formulation for pigs. Faecal endogenous $\mathrm{P}$ output contributes to a significant portion of the daily $P$ requirement and an inevitable source of metabolic $\mathrm{P}$ loss in weanling pigs.

\section{Acknowledgements}

This research was jointly supported by grants from Chinese Academy of Science Knowledge Innovation Project (KSCX2SW-323 and KSCX2-YW-N-022), National Basic Research Program of China (no. 2004CB117502), Program for Ganjiang Scholars and Innovative Research Team in Nanchang University (IRT0540), Natural Science Foundation of China (NSFC 30671517, 30371038, 30528006), and the Outstanding Overseas Chinese Scholars Fund of the Chinese Academy of Sciences (2005-1-4 and 2005-1-7).

\section{References}

Ajakaiye A, Fan MZ, Archbold T, Hacker RR, Forsberg CW and Phillips JP 2003. Determination of true phosphorus digestibility and the endogenous loss associated with soybean meal for growing-finishing pigs. Journal of Animal Science 81, 2766-2775.

Association of Official Analytical Chemists 1993. Official methods of analysis, 15th edition. AOAC, Washington, DC.

Fan MZ, Archbold T, Sauer WC, Lackeryam D, Rideout T, Gao Y, De Lange CFM and Hacker RR 2001. Novel methodology allows simultaneous measurement of true phosphorus digestibility and the gastrointestinal endogenous phosphorus outputs in studies with pigs. Journal of Nutrition 131, 2388-2396.

Farrell DJ and Hutton K 1990. Rice and rice milling by-products. In Nontraditional feed sources for use in swine production (eds PA Thacker and RN Kirkwood), pp. 339-353. Butterworth and Co. Ltd, London.

Jongbloed AW and Kemme PA 1990. Apparent digestible phosphorus in the feeding of pigs in relation to availability, requirement and environment. 1. Digestible phosphorus in feedstuffs from plant and animal origin. The Netherlands Journal of Agricultural Science 8, 567-575.

Jongbloed AW, Mroz Z and Kemme PA 1992. The effect of supplementary Aspergillus niger phytase in diets for pigs on concentration and apparent digestibility of dry matter, total phosphorus and phytic acid in different sections of the alimentary tract. Journal of Animal Science 70, 1159-1168.

Li JB, Li DF, Yin YL, Piao XS, He JH, Chen GP and Shu JC 2004. Performance, nutrient digestibility and intestinal disaccharidase activity of weaner/grower pigs given diets containing extruded Chinese stored brown rice with exogenous enzyme supplements. Animal Science 79, 429-438.

Liu J, Bollinger DW, Ledoux DR and Veum TL 2000. Effect of dietary calcium: phosphorus ratios on apparent absorption of calcium and phosphorus in the small intestine, cecum, and colon of pigs. Journal of Animal Science 78, 106-109.

National Research Council 1998. Nutrients requirements for swine, 10th edition. Academy Press, Washington, DC.

Saha DC and Gilbreath RL 1981. Analytical recovery of chromium from diet and feces determined by colorimetry and atomic absorption spectrophotometry. Journal of Science of Food Agriculture 55, 433-446.

Shen Y, Fan MZ, Ajakaiye A and Archbold T 2002. Use of the regression analysis technique to determine the true phosphorus digestibility and the endogenous phosphorus output associated with corn in growing pigs. Journal of Nutrition 132, 1199-1206.

Shen Y, Yin Y, Chavez ER and Fan MZ 2005. Methodological aspects of measuring phytase activity and phytate phosphorus content in selected cereal grains and digesta and feces of pigs. Journal of Agricultural and Food Chemistry 53, 853-859.

Statistical Analysis Systems Institute 1988. User's guide: statistics. SAS Institute Inc., Cary, NC.

Steel RGD and Torrie JH 1980. Principles and procedures of statistics: a biometrical approach, second edition. McGraw-Hill, New York, NY.

Weremko D, Fandrejewski H, Zebrowska T, Han K, Kim JH and Cho WT 1997. Bioavailability of phosphorus in feeds of plant origin for pigs. Asian Journal of Animal Science 10, 551-566.

Yin YL, Deng ZY, Huang RL, Li TJ and Zhong HY 2004. The effect of arabinoxylanase and protease supplementation on nutritional value of diets containing wheat bran or rice bran in growing pigs. Journal of Animal and Feed Sciences 13, 445-461. 
Yang, Li, Yin, Li, Wang, Wu, Huang, Kong, Yang, Kang, Deng, Wang, Tan, Hu, Xing, Wu, He, Yao, Liu, Tang, Yin, Deng, Xie and Fan

Yin YL, Huang RL and Zhong HY 1993a. Comparison of the ileorectal anastomosis and conventional method for the measurement of ileal digestibility of protein sources and mixed diets in growing pigs. Animal Feed Science and Technology 42, 297-308.

Yin YL, Huang RL, Zhong HY, Chen CM and Dai H 1991. Influence of different cannulation techniques on the pre-cecal digestibility of protein, amino acids and cell wall constituents from diets, containing different protein meal, in pigs. Animal Feed Science and Technology 35, 271-281.

Yin YL, Zhong HY, Huang RL, Chen CM, Li TJ and Pai YF 1993b. Nutritive value of feedstuffs and diets for pigs. IChemical composition, apparent ileal and fecal digestibility. Animal Feed Science and Technology $44,1-27$. 